\title{
Erratum to: Association of the ZFPM2 gene with antipsychotic-induced parkinsonism in schizophrenia patients
}

\author{
Lior Greenbaum • Robert C. Smith • Mordechai Lorberboym • Anna Alkelai • \\ Polina Zozulinsky • Tzuri Lifschytz • Yoav Kohn • Ruth Djaldetti • Bernard Lerer
}

Published online: 5 November 2011

(C) Springer-Verlag 2011

\section{Erratum to: Psychopharmacology}

\section{DOI 10.1007/s00213-011-2499-6}

In the version of the article initially published, the name of the sixth author was misspelled. Tzuri Lifschytz name appears correctly above and below.

\footnotetext{
The online version of the original article can be found at http://dx.doi. org/10.1007/s00213-011-2499-6.

L. Greenbaum • A. Alkelai • P. Zozulinsky • T. Lifschytz •

Y. Kohn · B. Lerer $(\bowtie)$

Biological Psychiatry Laboratory, Department of Psychiatry,

Hadassah-Hebrew University Medical Center,

Ein Karem,

Jerusalem 91120, Israel

e-mail: lerer@cc.huji.ac.il

R. C. Smith

Department of Psychiatry, New York University Medical School,

New York, NY, USA

R. C. Smith

Nathan Kline Institute for Psychiatric Research,

Orangeburg, NY, USA

M. Lorberboym

Department of Nuclear Medicine, Edith Wolfson Medical Center,

Holon, Israel

R. Djaldetti

Department of Neurology, Rabin Medical Center,

Petah Tiqwa, Israel

M. Lorberboym $\cdot$ R. Djaldetti

Sackler Faculty of Medicine, Tel Aviv University,

Tel Aviv, Israel
} 